
Military Technical College Kobry El-Kobbah, Cairo, Egypt.

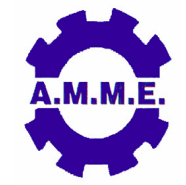

\title{
MECHANICAL AND WEAR BEHAVIOUR OF SOLUTION TREATED Ti-6Al-4V ALLOY
}

\author{
K. M. Ibrahim ${ }^{\star}$ and Y. Fouad
}

\begin{abstract}
Microstructural evaluation and wear characteristics of solution treated Ti-6Al-4V alloy have been investigated. The material was produced using vacuum induction furnace and then applying hot rolling at $900{ }^{\circ} \mathrm{C}$ to reduce the samples thickness from 30 to $12 \mathrm{~mm}$. One part of the material was water-quenched from a temperature above $\beta$ transus at $1100{ }^{\circ} \mathrm{C} / 60 \mathrm{~min}$. to produce a beta lamellar microstructure imbedded in some alpha phase. The other part was water quenched from a temperature below $\beta$ transus at $950{ }^{\circ} \mathrm{C} / 60 \mathrm{~min}$. to generate an equiaxed microstructure. The fine lamellar structure resulted in ultimate strength and wear resistance significantly superior to the equiaxed microstructure. The overall best combination of hardness, tensile properties, and wear resistance of the studied Ti-6Al-4V is achieved by solution treatment at $1100{ }^{\circ} \mathrm{C} / 60 \mathrm{~min}$. and the lowest values were obtained for the as-cast structure due to the heterogeneity in structure and large grain size that ranged from 350 to $50 \mu \mathrm{m}$.
\end{abstract}

\section{KEYWORDS}

Ti-6Al-4V, Solution treatment, Wear, Microstructure.

\footnotetext{
* Associate professor, Manufacturing Technology Dept., CMRDI, Cairo, Egypt. Email:khaledabouelela@yahoo.com).

** Lecturer, GUC, Cairo, Egypt.
} 


\section{INTRODUCTION}

Titanium alloys are widely used for industrial applications because they combine excellent mechanical properties with low density [1-3]. In particular, Ti-V-Al alloy system such as Ti-6Al-4V is widely used as industrial Ti-alloy $[4,5]$. Ti-6Al-4V has got great attention for many years due to its excellent mechanical properties, biocompatibility and corrosion resistance, etc [6,7]. For Ti-6Al-4V alloy, different microstructures can be obtained by applying thermomechanical treatment on cast or wrought alloy [8,9]. These treatments consist of a complex sequence of solution treatment, deformation, recrystallization, ageing and annealing for stress release [10]. Depending on whether the solution treatment temperature is above or below the $\beta$-transus temperature, the microstructure will be lamellae or equiaxed [11]. Slow cooling from the $\beta$-phase region results in a lamellae microstructure and the lamellae becomes coarser with reducing the cooling rate [12]. Indeed, the mechanical properties are dependent upon the microstructure features [13]. It is reported by Venkatesh et al. [14] that an improvement in $\alpha+\beta$ titanium alloys can be achieved by solution treatment above the beta transus temperature and rapid quenching in water or air cooling. However, the wear resistance of Ti-6Al-4V is still far from satisfying. Therefore, the wear behavior of Ti-6Al-4V that solution treated at above and below $\beta$ transus temperature is investigated.

\section{EXPERIMENTAL WORK}

In this study titanium alloy (Ti-6Al-4V) with a nominal composition of Ti-6.10Al-4.1V$0.17 \mathrm{Fe}-0.140$, in wt.\% was investigated. This alloy has a $\beta$ transition temperature around $998{ }^{\circ} \mathrm{C}$, at which $\alpha+\beta$ transformed to $\beta$. This Ti-alloy was produced by melting twice in a vacuum induction skull melting furnace and poured into a graphite mould as square bars with a dimension of $40 \times 40 \mathrm{~mm}^{2}$. The bars were machined down into $30 \times 30 \mathrm{~mm}^{2}$. Hot deformation was applied by rolling at $900{ }^{\circ} \mathrm{C}$ to reduce the samples thickness from $30 \mathrm{~mm}$ to $12 \mathrm{~mm}$, i.e., a reduction ratio of $60 \%$.

Two types of microstructure were produced by applying two different heat treatment conditions: one above the $\beta$-transus $\left(1100{ }^{\circ} \mathrm{C}\right.$ for $60 \mathrm{~min}$. and then water quenching) and the other below the $\beta$-transus $\left(950{ }^{\circ} \mathrm{C}\right.$ for $60 \mathrm{~min}$. and then water quenching). The microstructure of the various conditions was investigated using optical microscopy. The tensile test was performed at room temperature to investigate the mechanical properties of the heat treated conditions. The tensile samples were machined according to ASTM-E8 standard with a diameter and gauge length of 4 and $20 \mathrm{~mm}$, respectively. Adhesion wear test was carried out using pin-on-ring Tribometer testing machine. A rectangular test samples with dimensions of $8 \times 12 \times 12$ $\mathrm{mm}^{3}$ were fixed against a rotating stainless steel ring with a surface hardness of 63 HRC. Various rotating speeds of $1,1.25,1.5,1.75$ and $2 \mathrm{~m} / \mathrm{sec}$ were used with an applied load of $55 \mathrm{~N}$ for 30 min. Wear test was performed in dry condition at room temperature. The wear mechanism was discussed based on SEM observation. 


\section{RESULTS AND DISCUSSION}

\section{Microstructure}

The as-cast samples of the investigated Ti-6Al-4V alloy obtained a microstructure consisted of $\alpha+\beta$, Fig. 1a. It is considered a heterogeneous structure because it contains different sizes of $\beta$-grains that ranged from 350 to $500 \mu \mathrm{m}$. The $\alpha$-phase was located at the $\beta$-grain boundaries and inside the $\beta$-grains. On the other hand, the rolled samples showed fine equiaxed $\alpha+\beta$ structure due to the highly plastically deformation strain occurred by rolling, Fig. 1b. However, the heat treated samples showed another feature of microstructure that depends on the solution temperature. Generally, the heat treated samples at $1100{ }^{\circ} \mathrm{C}$ showed lamellae structure, and the other samples solution treated below the $\beta$-transus $\left(950{ }^{\circ} \mathrm{C}\right)$ obtained an equiaxed structure, Fig. $1 \mathrm{c}$, d. This is obvious in the pseudo-binary diagram shown in Fig. 2 [15] for the Ti-6Al-4V alloy. Moreover, water quenching from $1100{ }^{\circ} \mathrm{C}$ obtained mostly $\beta$-phase and some island of $\alpha$. The formation of $\alpha$ in the structure could be due to the insufficient cooling rate during quenching. However the samples quenched from $950{ }^{\circ} \mathrm{C}$ showed a homogenous fine $\alpha+\beta$ structure $[16,17]$.

\section{Mechanical Properties}

Figure 3 shows Vickers hardness measurements for each experimental condition of the investigated Ti-6Al-4V alloy. The as-cast condition obtained the lowest hardness value of $340 \mathrm{HV}$ due to the presence of coarse $\beta$-grains and also existing of relatively heterogeneity in the $\alpha-\beta$ structure. Due to the severe plastic deformation that was applied by rolling on the cast samples, the hardness increased to $375 \mathrm{HV}$. Maximum hardness was reported for the samples solution treated at above $\beta$-transus (1100 ${ }^{\circ} \mathrm{C} / \mathrm{WQ}$ ), where the hardness value reach to $460 \mathrm{HV}$. But the treated samples below the $\beta$-transus (950 $\left.{ }^{\circ} \mathrm{C} / \mathrm{WQ}\right)$ showed lower hardness value $(400 \mathrm{HV})$ compared to the last one due to the existing of higher amount of $\alpha$-phase[17].

The tensile properties of Ti-6Al-4V have been determined and it is found that they are mainly dependent on the microstructure feature, Fig. 4. The as-cast structure obtained UTS of $1080 \mathrm{MPa}$ which is compatible for the coarse $\alpha+\beta$ structure with a coarse grain size. Because the as-cast structure is normally heterogeneous, it obtains the lowest elongation percent of $5.6 \%$. By applying the rolling process, the UTS increased to $1130 \mathrm{MPa}$ due to increasing the dislocation density as well as decreasing the grain size. Maximum UTS was obtained for the solution treated samples at $1100 \mathrm{C}(1370 \mathrm{MPa})$ because their structure that consisted of fine lamellae structure of $\beta$-phase and relatively small amount of $\alpha$ and $\alpha$ '. On the other hand, the eqiaxed structure obtained relatively low UTS (1226 MPa) due to the presence of primary $\alpha^{\prime}$ and $\alpha$-phases which are responsible for decreasing the strength of the alloy.

The tribological properties of the investigated Ti-6Al-4V alloy against stainless steel ring are shown in Fig. 5. The effect of sliding speeds on wear rate of all studied conditions is investigated. The estimated values of wear rates in all conditions indicated that the wear rates increase with increasing sliding speed. It was reported in an earlier study of Alam et al. [18] that under a constant load of $45 \mathrm{~N}$, there was an 
increase in wear rate with increasing the sliding speed up to $500 \mathrm{rpm}$. Thereafter, a steady state is attained and there no any change in the wear rate. Moreover, the Archard's low proved that the volumetric loss of the material is inversely proportional to the hardness value of the material [19]. This implies that the higher hardness of the material, the smaller is the volume loss. The investigated Ti-6Al-4V alloy exhibits significant difference in hardness values for the studied conditions, therefore the experimental sliding wear data correlate well with Archard's low. The heat treated samples at $1100{ }^{\circ} \mathrm{C}$ showed the lowest wear rate among all other investigated conditions due to the highest hardness value compared to the others.

The worn surfaces of some selected samples have been studied using SEM. The SEM micrographs show typical worn surface morphologies of the samples tested at low medium and high sliding speeds. Evidences of continuous sliding marks with plastically deformed grooves are seen on the wear tracks independently of the sliding speed. However, the extent of plastic deformation or ploughing is found to be higher in case of high sliding speed $(2 \mathrm{~m} / \mathrm{sec})$, Fig. 6 e,f. Only shallow grooves and scratching on the samples surfaces can be observed in case of low sliding speed (1 $\mathrm{m} / \mathrm{sec}$ ), Fig. 6 a,b. In addition, the medium speed $(1.5 \mathrm{~m} / \mathrm{sec}$ ) showed moderate feature of worn surface that can be described as tire track wear mode, Fig. $6 \mathrm{c}$,d. Lamination wear mechanism can be also seen with low sliding speed and it is found to be more clearly for the heat treated samples at $950{ }^{\circ} \mathrm{C}$ because they have lower hardness value, Fig. 6 a.

\section{CONCLUSIONS}

In this study, the influence of applying different solution treatment processes on microstructure and mechanical properties as well as wear behavior of Ti-6Al-4V alloy was evaluated. Therefore, this work can be concluded as follows:

1. The as-cast structure obtained a heterogeneous $\alpha+\beta$ structure that has a large grain size ranged from 350 to $500 \mu \mathrm{m}$ and the rolled samples obtained a very fine equiaxed $\alpha+\beta$ structure.

2. Fine $\beta$-lamellar structure with $\alpha$-island was obtained by rapid quenching in water from $1100{ }^{\circ} \mathrm{C}$, and an equiaxed structure was formed by quenching from $950{ }^{\circ} \mathrm{C}$.

3. A more suitable combination of hardness and tensile properties can be obtained by solution treatment at a temperature above the $\beta$-transus at 1100 ${ }^{\circ} \mathrm{C}$.

4. Hardness was shown to be an important factor especially when wear is involved. Accordingly, the solution treatment at $1100{ }^{\circ} \mathrm{C}$ for the investigated Ti-6Al-4V alloy is the most suitable microstructure for getting a minimum wear rate.

\section{REFERENCES}

[1] Lee H., Mall S., Allen W.Y., Fretting fatigue behavior of shot-peened Ti-6Al-4V under seawater environment, Mater. Sci. Eng. A, 420, pp. 72-78, (2006). 
[2] Rocha S.S., Adabo G.L, Henriques G.E.P., M.A. Nobilo, Veckers hardness of cast commercially pure titanium and Ti-6Al-4V alloy submitted to heat treatments, Braz. Dent. J., 17 (2), pp. 126-129, (2006).

[3] Sen I., Tamirisakanadala S., Miracle D.B., U. Ramamurty, Mirostructural effects on the mechanical behavior of B-modified Ti-6Al-4V alloys, Acta Mater., 55, pp. 4983-4993, (2007).

[4] Matsumoto H., Yoneda H., Sato K., Kurosu S., Maire E., Fabregue D., Konno T.J., Chiba A., Room-temperature ductility of Ti-6Al-4V alloy with $\alpha^{\prime}$ martensite microstructure, Mater. Sci. Eng. A, 528, pp. 1512-1520, (2011).

[5] Niinomi M., Recent research and development in titanium alloys for biomedical applications and healthcare goods, Sci. Tech. Advanced Mater., 4, pp. 445-454, (2003).

[6] Zhang W., Wang C., Liu W., Tribological behaviors of Ti-6Al-4V modified by chemical methods, Tribology Intern., 43, pp. 228-234, (2010).

[7] Wang K., The use of titanium for medical applications in the USA, Mater. Sci. Eng. A, 213, pp. 134-137, (1996).

[8] Tamirisakandala S., Vedam B.V., Bhat R.B., Recent advances in the deformation processing of titanium alloys, J. Mater. Eng. Perfor., 12, pp. 661673, (2003).

[9] Ibrahim K.M., Mhaede M., Wagner L., Mechanical properties of titanium alloys produced in Egypt, The $12^{\text {th }}$ Intern. Conf. of Titanium, Beijing-China, 19-24 June (2011).

[10] Collins P.C., Welk B., Searles T., Tiley J., Russ J.C., Fraser H.L., Development of methods for the quantification of microstructural features in $\alpha+\beta$ processed $\alpha / \beta$ titanium alloys, Mater. Sci. Eng. A, 508, pp. 174-182, (2009).

[11] Luetering G., Williams J.C., Titanium, Springer-Verlag Berlin, Germany, (2003).

[12] Ibrahim K.M., Mhaede M., Wagner L., Microstrucre and mechanical properties of Ti-6Al-4V cast in Egypt, $1^{\text {st }}$ Inter. ICF Conf. in Middle East and Africa, LuxorEgypt, 14-17 Nov. (2011).

[13] Motyka M., Kubiak K., Sieniawski J., Microstructural transformation of $\beta$-solution treated and forged Ti-6Al-4V alloy during superplastic deformation, Proc. $11^{\text {th }}$ World Conf. on Titanium, Japan, pp. 1009-1012, (2007).

[14] Venkatesh B.D., Chen D.L., Bhole S.D., Effect of heat treatment on mechanical properties of Ti-6Al-4V alloy, J. Mater. Sci. Eng. A, 506, pp. 117-124, (2009).

[15] Atapour M., Pilchak A., Frankel G.S., Williams J.C., Corrosion behaviour of investment cast and friction stir processed Ti-6Al-4V, Corr. Sci., 52, pp. 30623069, (2010).

[16] Alagic I.C., Cvijovic Z., Mitrovic S., Panic V., Rakin M., Wear and corrosion behaviour of $\mathrm{Ti}-13 \mathrm{Nb}-13 \mathrm{Zr}$ and $\mathrm{Ti}-6 \mathrm{Al}-4 \mathrm{~V}$ alloys in simulated physiological solution, Corr. Sci., 53, pp. 796-808, (2011).

[17] Leyens C., Peters M., Titanium and titanium alloys, Wily-VCH Verlag GmbH, Germany, (2003).

[18] Alam O., Haseeb A.S., Response of Ti-6Al-4V and Ti-24Al-11Nb alloys to dry sliding wear against hardened steel, J. Tribology Intern., 35, pp. 357-362, (2002).

[19] Alagic I.C., Cvijovic Z., Mitrovic S., Panic V., Rakin M., Wear and corrosion behavior of $\mathrm{Ti}-13 \mathrm{Nb}-13 \mathrm{Zr}$ and $\mathrm{Ti}-6 \mathrm{Al}-4 \mathrm{~V}$ alloys in simulated physiological solution, Corr. Sci., 53, pp. 796-808, (2011). 


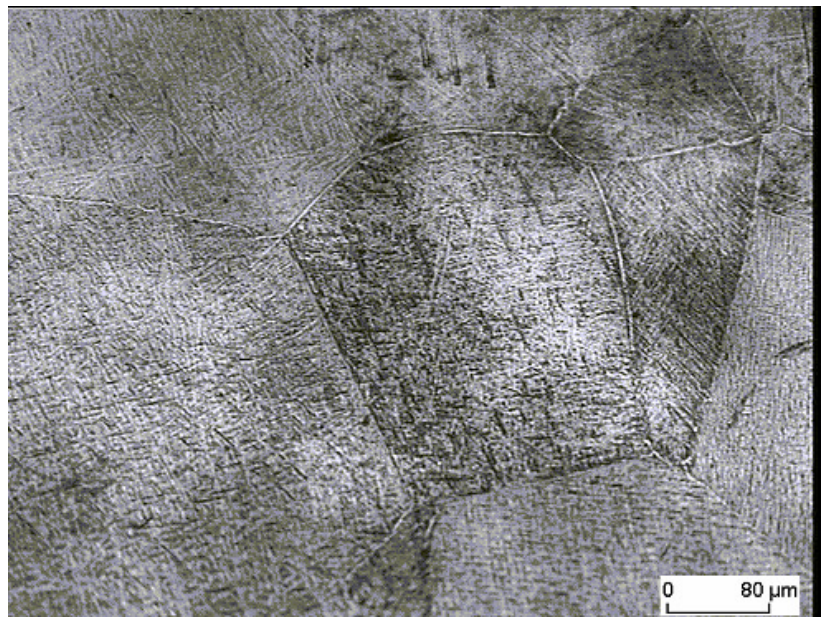

a-

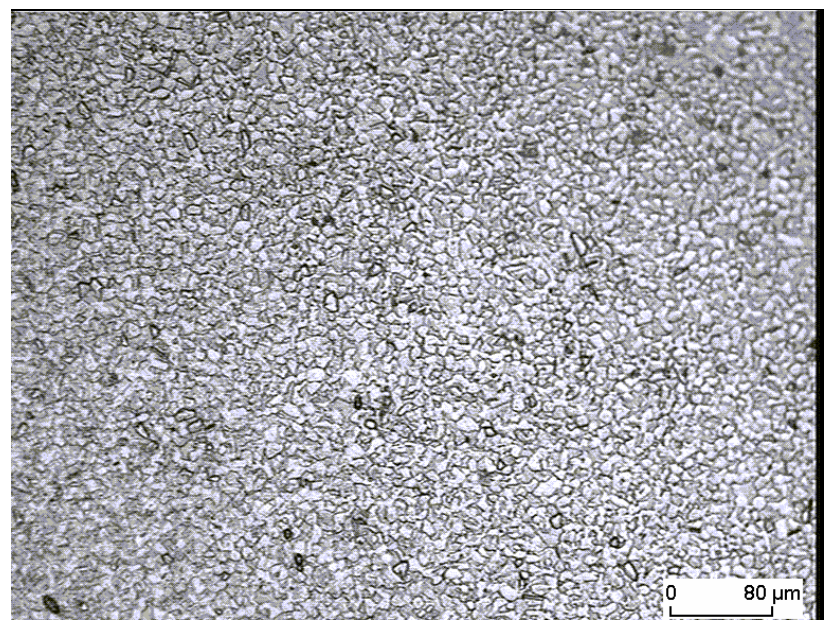

C-

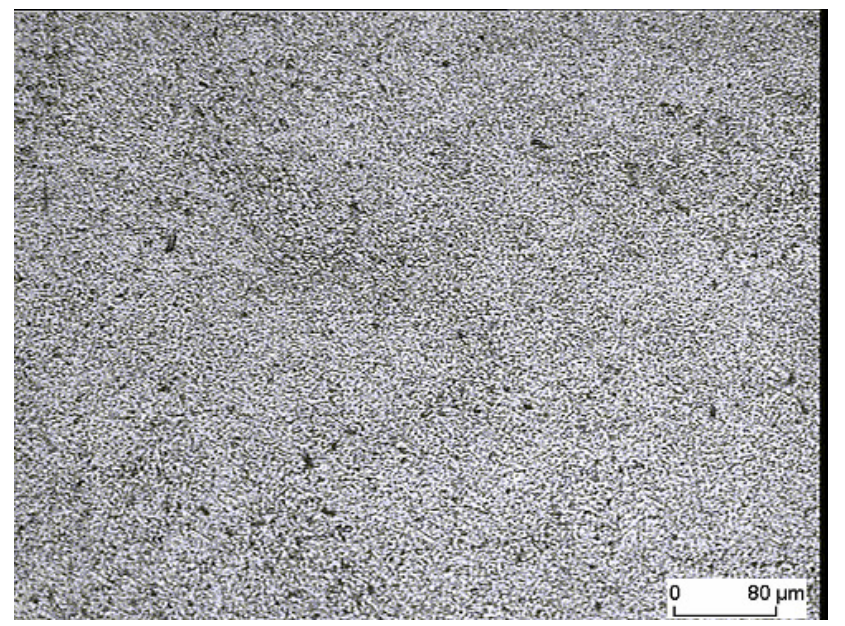

b-

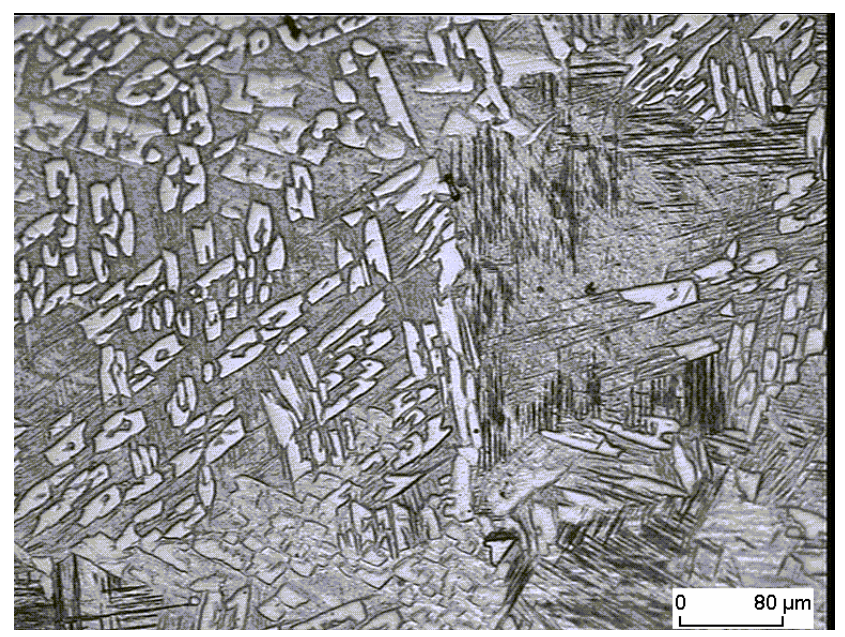

d-

Fig. 1: Microstructure of the investigated Ti-6Al-4V in different conditions;
a- As-cast
b- Rolled
c- Solution treated at $950{ }^{\circ} \mathrm{C}$
d- Solution treated at $1100{ }^{\circ} \mathrm{C}$ 


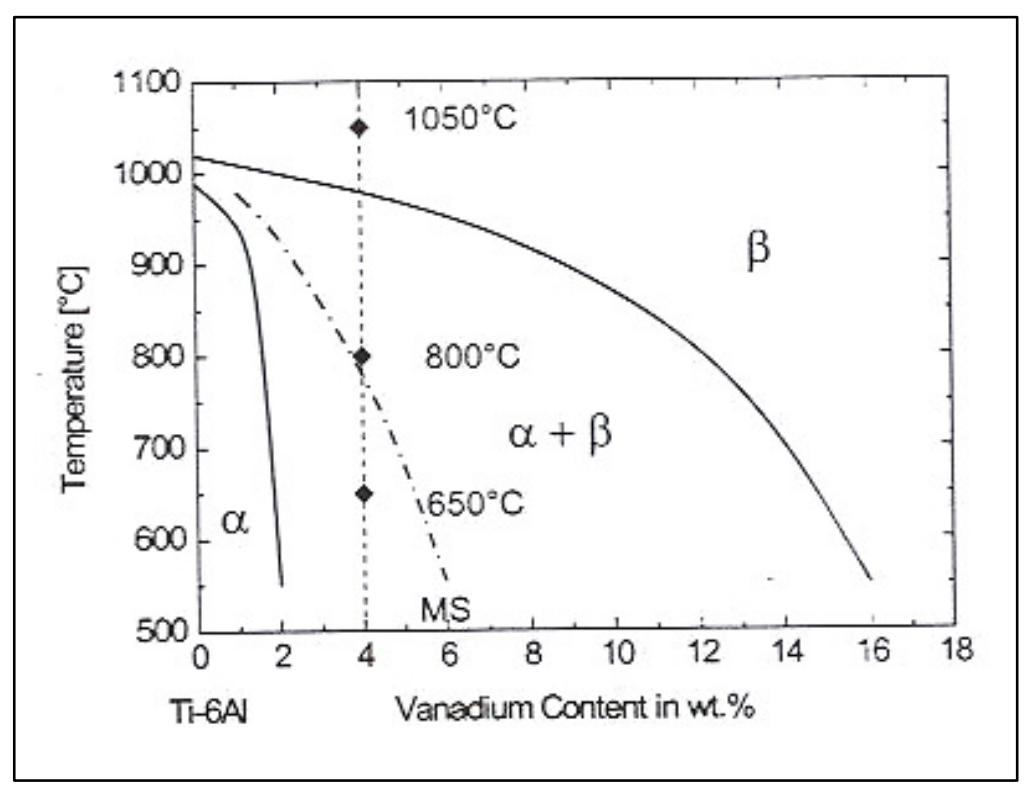

Fig. 2: Section of the ternary phase diagram of Ti-6Al-4V at constant aluminum content of $6 \%$

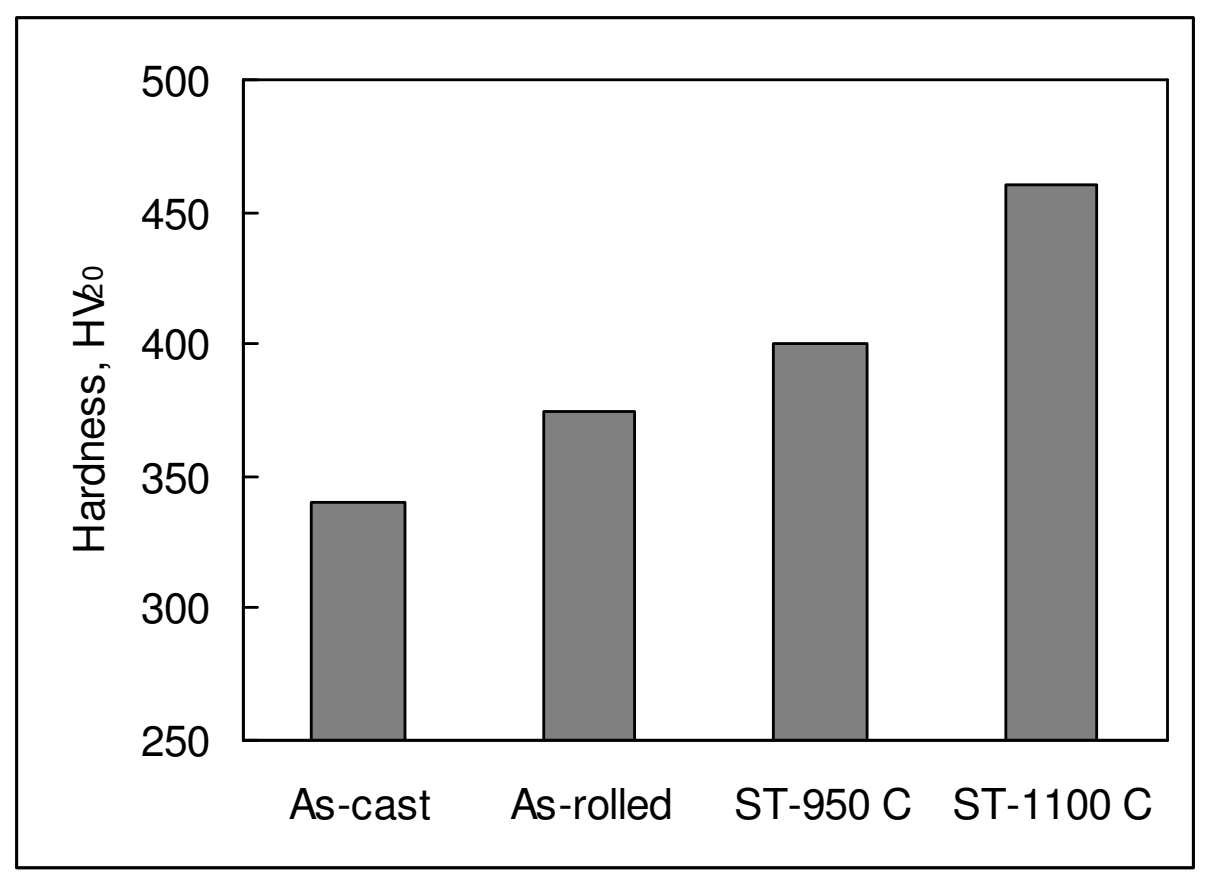

Fig. 3: Hardness values of the studied different conditions 


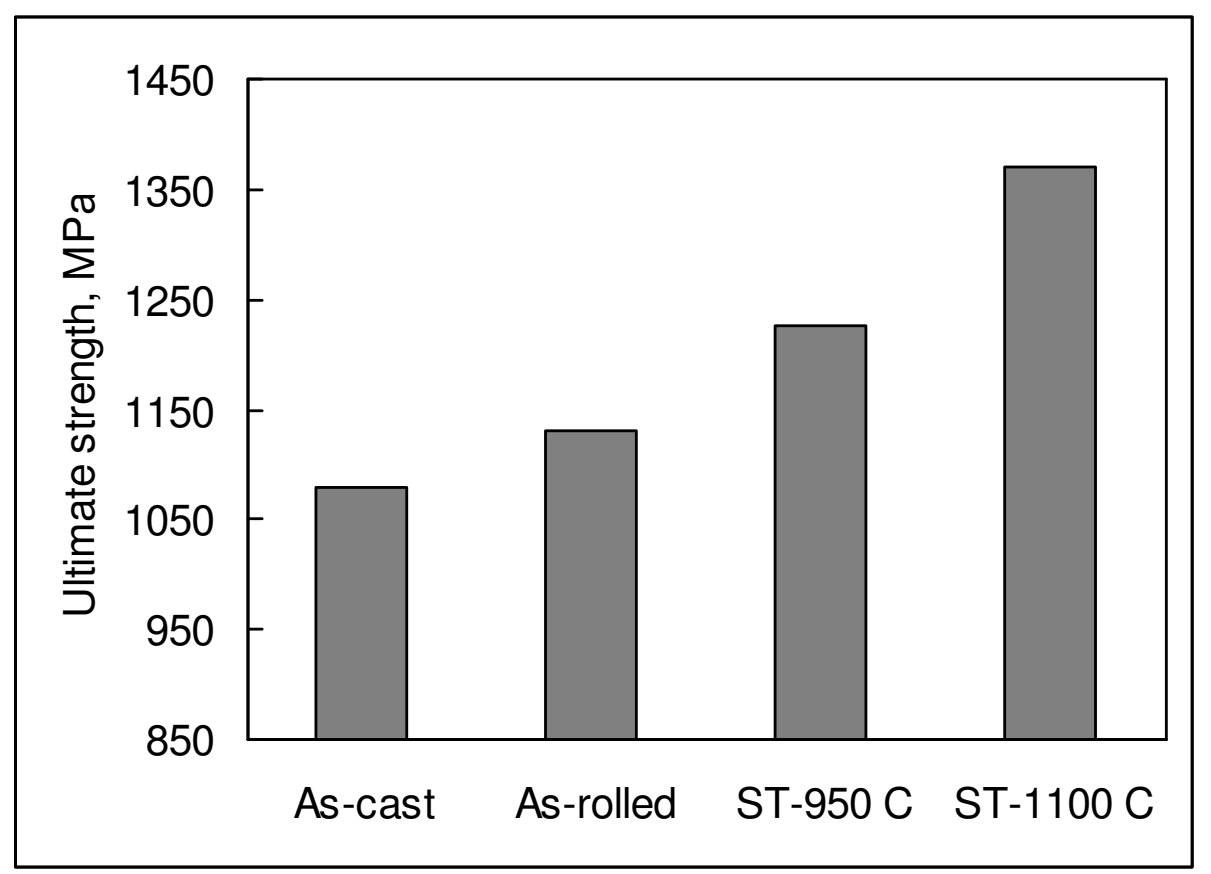

Fig. 4: Tensile strength of the studied conditions

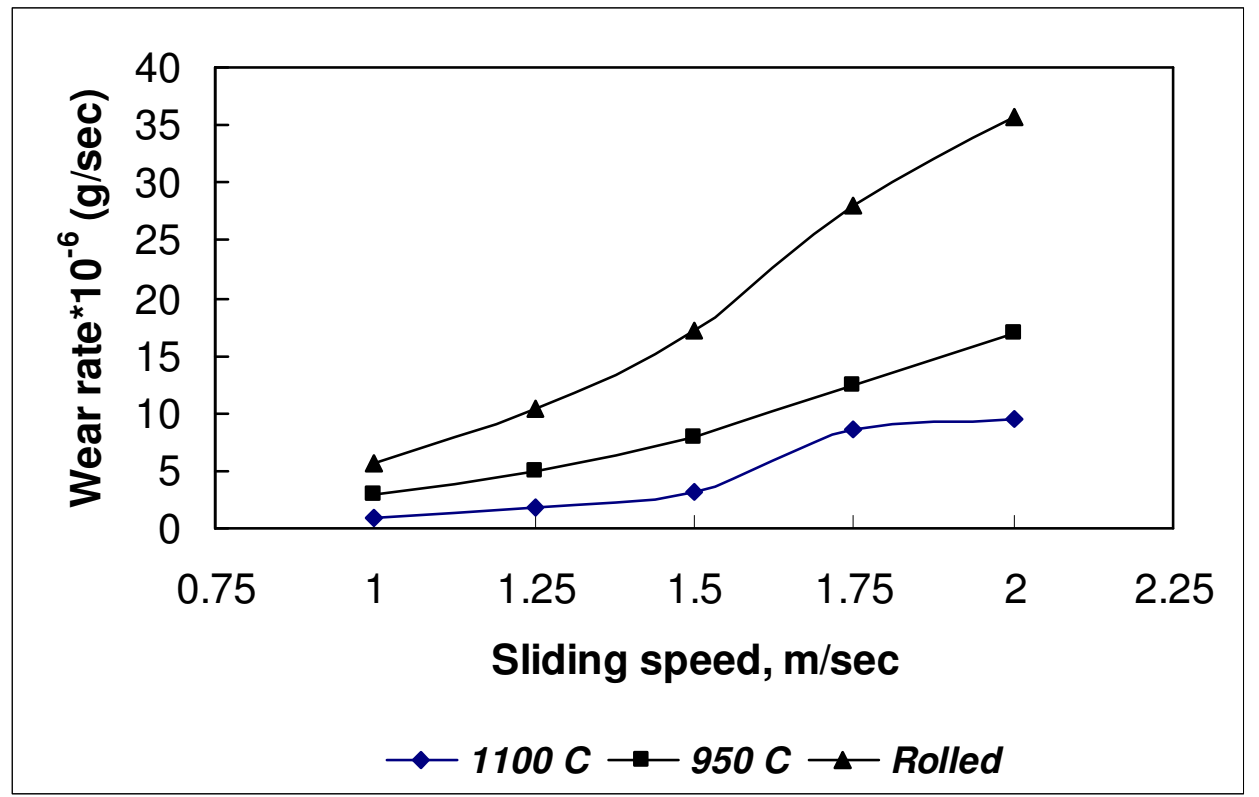

Fig. 5: Wear rate of the studied Ti-alloy in the as-rolled and solution treated conditions 


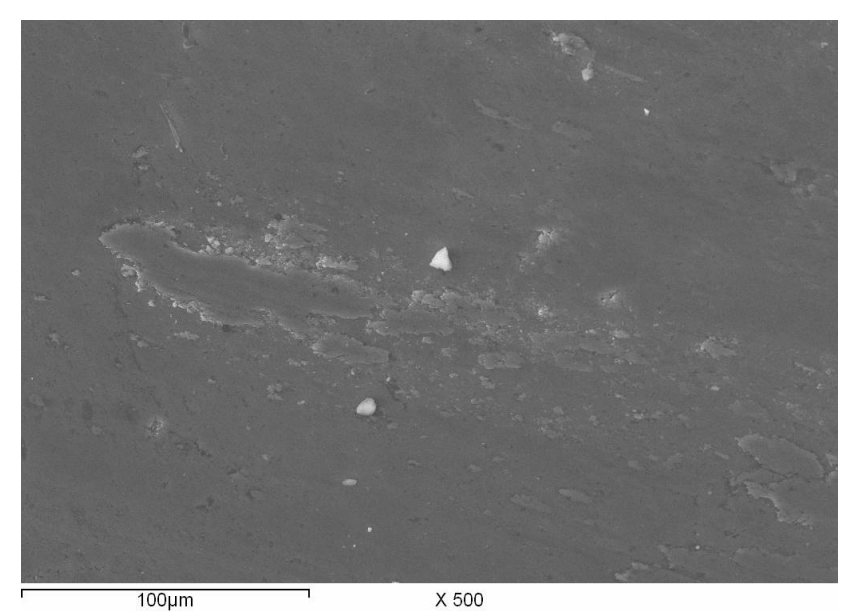

a- $1 \mathrm{~m} / \mathrm{s}$

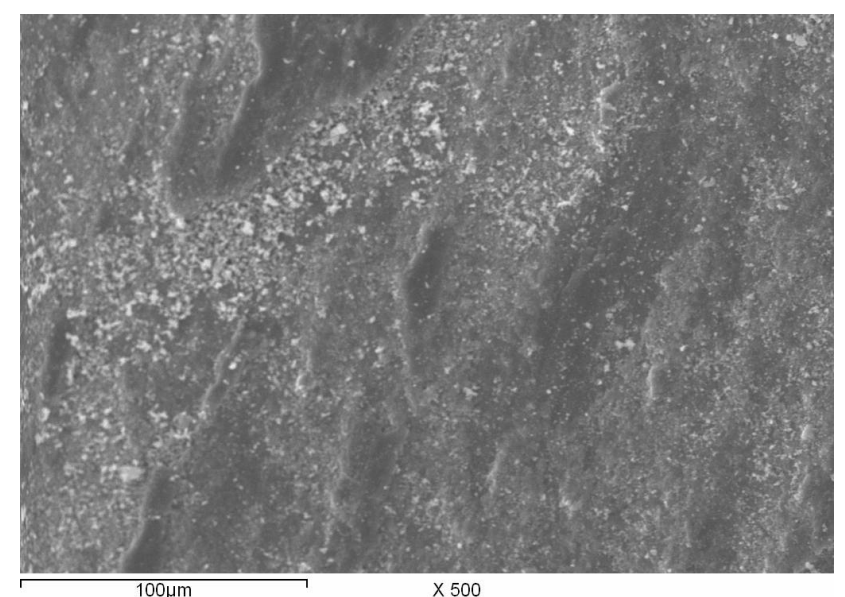

c- $1.5 \mathrm{~m} / \mathrm{s}$

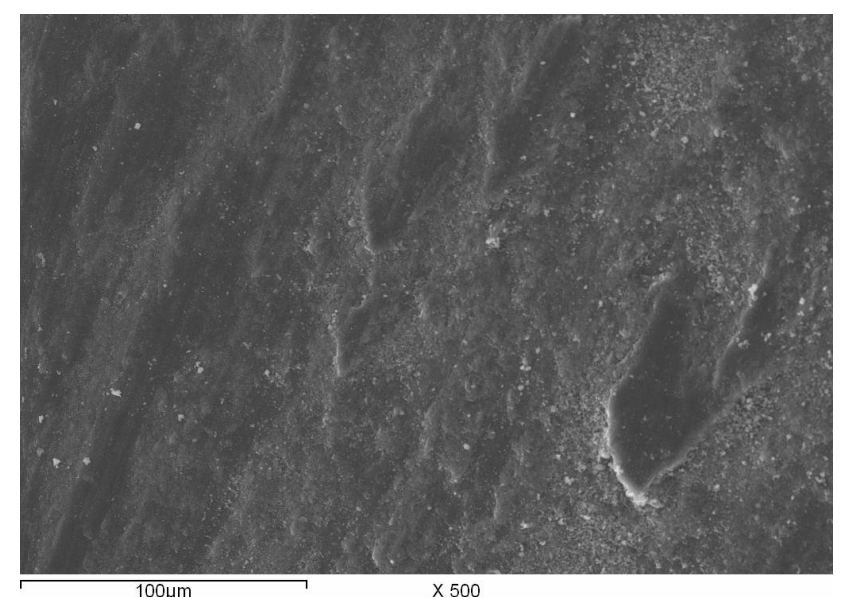

$100 \mu \mathrm{m}$

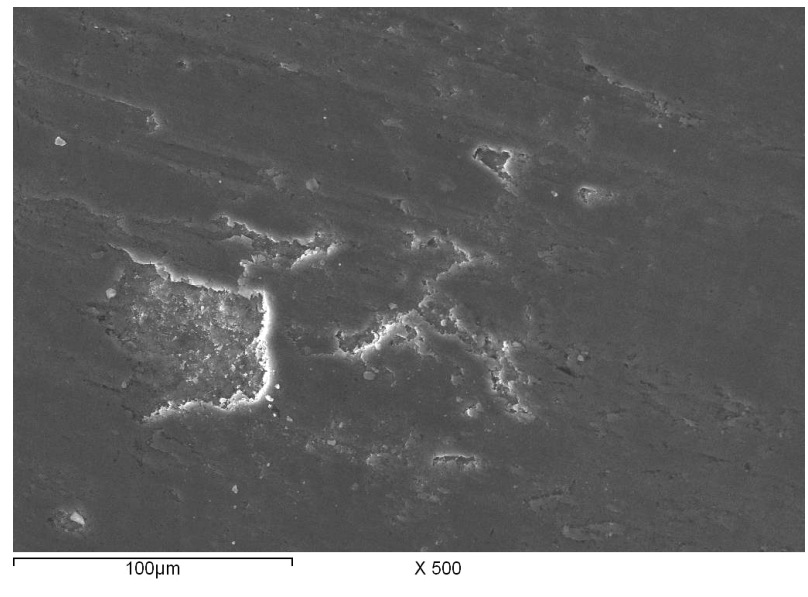

b- $1 \mathrm{~m} / \mathrm{s}$

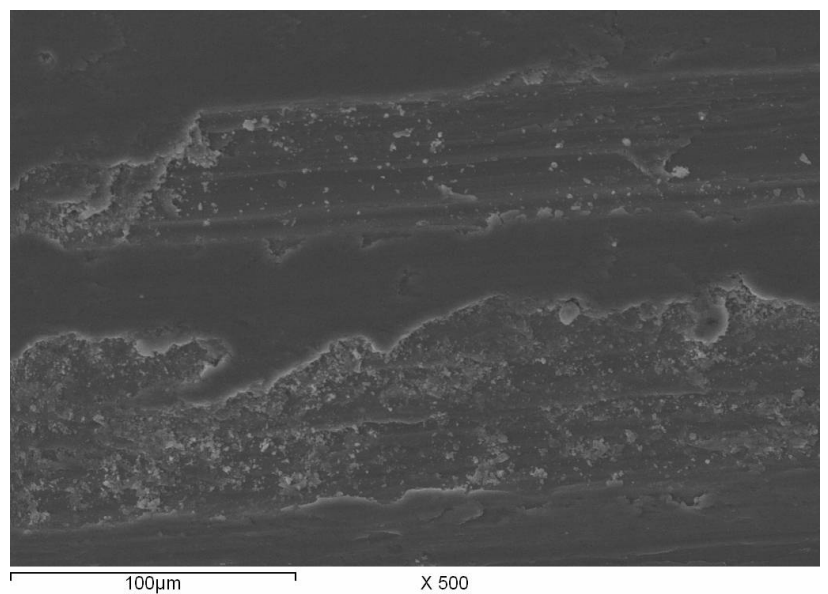

d- $1.5 \mathrm{~m} / \mathrm{s}$

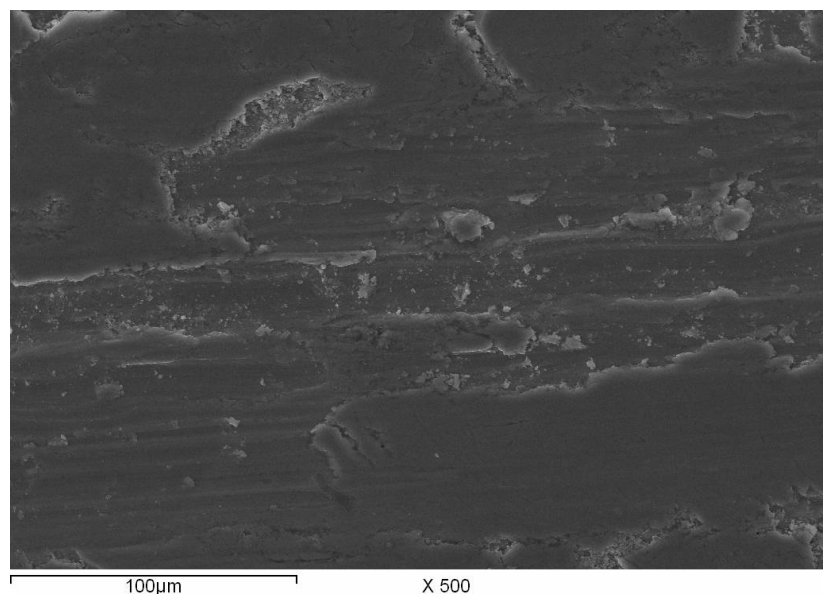

f- $2 \mathrm{~m} / \mathrm{s}$ $\mathrm{ST}=950^{\circ} \mathrm{C}$

Fig. 6: Worn surfaces investigation of the investigated Ti-6AI-4V alloy using SEM. 